\title{
Pesquisas e Documentos Curriculares no Âmbito da Educação Matemática de Jovens e Adultos
}

\author{
Research and Curriculum Documents within the Youth and Adults \\ Mathematics Education
}

\author{
Gilberto Januario* \\ Adriano Vargas Freitas ${ }^{* *}$ \\ Katia Lima***
}

\begin{abstract}
Resumo
Neste artigo, apresentamos resultados de três estudos desenvolvidos no âmbito de um projeto que analisou pesquisas e documentos curriculares na área de Educação Matemática, referentes à EJA. Um deles, no modelo de estado da arte, apresenta análises das publicações em periódicos da listagem Qualis (2000 a 2010). Os outros dois orientam-se pelas questões: Quais são as recomendações dos documentos oficiais da EJA para o ensino de Matemática? Os materiais didáticos estão de acordo com essas recomendações? Os resultados do projeto nos revelam, dentre outros destaques, verificação da convergência à defesa da não adoção de prescrição prévia de um currículo para a EJA, ocorrência nos documentos oficiais de recomendações favoráveis e potencialmente promotoras da enculturação matemática e indicações de utilização de conteúdos como forma de desenvolvimento de uma rede de relações, possibilitando uma pluralidade de significados dos conceitos e atividades.
\end{abstract}

Palavras-chave: Currículos de Matemática. Pesquisas sobre EJA. Educação de Jovens e Adultos. Educação Matemática.

\begin{abstract}
In this article, we present results of three studies conducted in the project that analyzed research and curriculum documents in the area of mathematics education in EJA. One of them, a state-of-the-art model, presents analysis of publications in journals of the Qualis listing (2000-2010). The other two are guided by the questions: What are the recommendations in the official documents of the EJA for teaching mathematics? Educational materials are in accordance with those recommendations? Among other results, we list: the verification of the defense

\footnotetext{
* Doutorando em Educação Matemática pela Pontifícia Universidade Católica de São Paulo (PUC-SP). Professor das Faculdades Guarulhos (FG), Guarulhos, SP, Brasil. Endereço para correspondência: Rua Barão de Mauá, 95, Centro, CEP: 07012-040, Guarulhos, SP, Brasil.E-mail: januario@uol.com.br.

** Doutor em Educação Matemática pela Pontifícia Universidade Católica de São Paulo (PUC-SP). Professor Adjunto da Universidade Federal Fluminense (UFF) - Instituto de Educação de Angra dos Reis, RJ, Brasil. Endereço para correspondência: Avenida do Trabalhador, 179, Jacuecanga, CEP: 23914-360, Angra dos Reis, RJ, Brasil.E-mail: adrianovargas@id.uff.br.

**** Doutoranda em Educação Matemática pela Pontifícia Universidade Católica de São Paulo (PUC-SP). Professora da Secretaria Municipal de Educação de São Paulo (SME-SP), São Paulo, SP, Brasil. Endereço para correspondência: Rua Doutor Diogo de Faria, 1247, $3^{\circ}$ andar, sala 309, Vila Clementino, CEP: 04037-004, São Paulo, SP.E-mail: katiaclimas@gmail.com.
} 
convergence for not adopting a prior prescription curriculum for adult education, occurring in official documents and recommendations favorable potentially to promote enculturation of mathematics, and indications of content used as a way to develop a network of relationships, providing a plurality of meanings for the concepts and activities.

Keywords: Mathematics Curriculum. Researches about EJA. Youth and Adult Education. Mathematics Education.

\section{Considerações iniciais}

Apresentamos um recorte de estudos desenvolvidos no Grupo de Pesquisa Desenvolvimento Curricular em Matemática e Formação de Professores, da Pontifícia Universidade Católica de São Paulo e, em seu interior, do projeto "O currículo de Matemática na Educação de Jovens e Adultos: dos intervenientes à prática em sala de aula", no qual destacamos o interesse de seus participantes em identificar e analisar currículos de Matemática para a Educação de Jovens e Adultos (EJA) e contribuir com reflexões para que estes currículos atendam às necessidades de aprendizagem dessa modalidade de ensino.

A Lei nº 9394/96, de Diretrizes e Bases para a Educação Nacional (BRASIL, 1996), ao destacar a necessidade de ofertar educação básica a jovens e adultos, atentando-se para características e modalidades adequadas às necessidades e disponibilidade desse público, instigou a comunidade acadêmica a desenvolver investigações sobre a modalidade de ensino EJA. A publicação das Diretrizes Curriculares Nacionais para a Educação de Jovens e Adultos (BRASIL, 2000) e das orientações curriculares para primeiro e segundo segmento da EJA, em especial às recomendações para o ensino de Matemática (BRASIL, 2002), trouxe contribuições às discussões e à reflexão sobre o ensino destinado a esse alunado, especialmente ao destacar que a EJA precisa ser concebida como um modelo pedagógico próprio, objetivando criar um ambiente propício a promover situações de aprendizagem que venham ao encontro das necessidades de jovens e adultos.

Nesse contexto, em que a questão da especificidade de uma modalidade se confronta com objetivos comuns que ela precisa ter em relação à educação chamada regular, emergem muitas questões a serem respondidas por pesquisadores, tais como as relativas aos currículos prescritos, apresentados, moldados e avaliados e concepções e crenças relativas a ensinar Matemática para pessoas jovens e adultas.

Emergem também questionamentos relacionados à falta de amplo conhecimento das diferentes dimensões que envolvem as realidades vivenciadas por estes aprendentes, que lhes abram maiores possibilidades de serem incluídos no processo educacional; e ao envolvimento 
em ações educativas que, em grande parte, encontram-se presas a paradigmas metodológicos relacionados a currículos tecnicistas inchados e distantes de uma realidade atual. Consideramos que significa, por fim, conhecer formas para que a educação que lhes seja dirigida propicie um processo contínuo de reestruturação desse indivíduo estudante em três dimensões básicas e indissociáveis: a individual, a profissional e a social.

Os recortes dos estudos apresentados nas páginas a seguir buscaram delinear parte destas questões direcionadas ao que é vivenciado pelo aluno jovem, adulto e idoso que, ao retornarem aos espaços escolares, têm por hábito se diferenciar dos demais grupos de estudantes por apresentarem de forma mais acentuada um comprometimento com a sua aprendizagem e, por isso, quase sempre apresentarem maiores necessidades de conhecer os motivos pelos quais devem aprender este ou aquele conteúdo.

Destacamos que, embora a nomenclatura Educação de Jovens e Adultos possa nos remeter a uma gama de estudantes "selecionados" por sua idade, na realidade, será de uma forma geral a sua caracterização sociocultural, sua história de exclusão e de falta de oportunidades anteriores, que servirão de "corte" para a entrada nessa modalidade.

A permanência desses estudantes nessa modalidade de ensino é, muitas vezes, marcada por grandes tensões, acusadas nas pesquisas desenvolvidas por Haddad (2000), tais como o dilema vivenciado pela EJA de pretender oferecer a escolarização básica e, ao mesmo, tempo levantar expectativas de mudanças no cotidiano de seus alunos, em especial na questão profissional, que não dependem apenas da escola. Os estudantes de EJA ouvidos pelo pesquisador relataram sua percepção da importância da escola para sua ascensão social e econômica, porém indicaram perceber certo distanciamento entre os conhecimentos transmitidos por ela e a sua vivência cotidiana.

Iniciamos apresentando um panorama das pesquisas publicadas em periódicos pertencentes à Listagem Qualis - CAPES/MEC (FREITAS, 2013) que indicam convergências da Educação Matemática e EJA, seguimos com recorte de um estudo das prescrições curriculares para a EJA (JANUARIO, 2012) e de duas coleções de livros didáticos aprovados para essa modalidade de ensino (SANTANA, 2012), o que possibilitou encontrarmos a ocorrência nos documentos oficiais de recomendações favoráveis, e potencialmente promotoras da enculturação matemática, e indicações de utilização de conteúdos como forma de desenvolvimento de uma rede de relações, possibilitando uma pluralidade de significados dos conceitos e atividades. 


\section{Educação Matemática nos currículos da EJA: estado da arte das publicações em periódicos}

Nesta primeira seção apresentamos uma visão panorâmica sobre publicações acerca de currículos da Educação de Jovens e Adultos, com um foco especial sobre as contribuições que a Educação Matemática tem proporcionado a essa modalidade de ensino como forma de (re)conhecimento das realidades históricas e atuais dessa parcela significativa da população brasileira em especial, mas também de outras partes do mundo.

Analisamos que, ao optarmos por apresentar um estado da arte de um assunto tão abrangente e rico de significações e análises, abraçamos um ambicioso projeto que sempre apresentará lacunas e omissões, mas que poderá significar o reconhecimento do esforço de muitos pesquisadores, de muitos educadores, enfim, de diversos brasileiros e estrangeiros envolvidos em um permanente processo que busca tornar possível a expressão buscamos uma escola de qualidade para todos.

Nosso estado da arte em Educação Matemática da Educação de Jovens e Adultos foi desenvolvido a partir da seleção e leitura de artigos publicados em periódicos nacionais e estrangeiros pertencentes à Listagem Qualis da CAPES/MEC, no período de 2000 a 2010, na área de Ensino de Ciências e Matemática. Do ponto de vista da relevância social e acadêmica, buscamos em nosso estudo a construção de material que possa referenciar discussões sobre o tema, reflexões e também o redimensionamento teórico-prático de projetos políticos pedagógicos relacionados à EJA e, em especial, à área de Matemática.

Com relação aos periódicos, Gil (2008, p. 62) considera que estes constituem atualmente o meio mais importante para a comunicação científica e, graças a eles, é que "vem se tornando possível a comunicação formal dos resultados de pesquisas originais e a manutenção do padrão de qualidade na investigação científica". Para Rocha e Salvi (2010), a opção por utilizar revistas científicas como fonte de pesquisa é uma forma otimizada de ter contato com grande parte da produção teórica produzida atualmente e que, por isso, as próprias revistas acabam se firmando como excelentes veículos de circulação mais rápidos e práticos entre pesquisadores, professores e especialistas das mais diversas áreas.

Para o trabalho de busca e análise dos periódicos que fizeram parte do espaço amostral, optamos por desenvolver um trabalho em que almejamos ter contato com cada uma das edições disponíveis, número a número, artigo a artigo dos periódicos 
selecionados ${ }^{1}$. Nosso intuito foi o de aumentar a amplitude e validade da pesquisa e por consequência sua credibilidade. Embora tal opção tenha nos exigido tempo e desgaste físico maior, ela foi necessária, visto que diversas publicações não contam ainda com um sistema de busca eficiente e, em alguns casos, mesmo possuindo um bom sistema de busca, não disponibilizam o resumo ou as palavras-chave de todos os artigos.

Desse modo, após concluída essa primeira etapa de seleção de dados, verificamos que os 95 periódicos destacados disponibilizaram um total de 15.828 artigos no período de 2000 a julho de 2010. Depois de análises de seus conteúdos e selecionarmos os artigos que se enquadravam em nossa pesquisa, reduzimos essa quantidade para 135 artigos.

Após releituras das produções selecionadas optamos por separá-las em temas que compuseram nossa análise. Neste artigo destacaremos os resultados relativos ao tema Currículo da EJA.

Entretanto, antes de delinearmos esses resultados, consideramos importante destacar que o nosso entendimento de leitura se baseou nos estudos de Chartier (2009), para quem a leitura é sempre uma prática criadora, inventiva e produtora e que, portanto, as significações dos textos, quaisquer que sejam, serão constituídas pelo leitor/analista diferencialmente pelas leituras que se apoderam desses textos. $\mathrm{O}$ ato de ler dá ao texto lido significações plurais e móveis, situadas no encontro das diversas formas de ler (coletivas ou individuais, herdadas ou inovadoras, íntimas ou públicas) e dos protocolos de leitura depositados no objeto lido pelo autor que busca indicar a compreensão de seu texto.

Para o processo de análise dos artigos, optamos pela análise textual discursiva (MORAES; GALIAZZI, 2011), cujas características propiciam uma pesquisa qualitativa envolvendo análises criteriosas de textos diversos e, a partir daí, uma melhor compreensão dos fenômenos investigados, para, em seguida, culminarem no desenvolvimento de um metatexto que seja representativo desse movimento.

O tema Currículos da EJA envolveu 19 produções selecionadas e um total de 34 autores/pesquisadores, sendo 30 deles vinculados a instituições de ensino de nível superior, (23 ligados a instituições públicas e 7 a particulares), 3 a uma mesma organização não governamental e 1 vinculado a instituição de Ensino Médio pertencente à rede pública de Contagem (MG).

\footnotetext{
${ }^{1}$ Aplicamos quatro delimitadores em nossa seleção de artigos: (a) seriam analisados os periódicos classificados por A1, A2, B1, B2, B3, B4 ou B5; (b) o período analisado compreenderia janeiro de 2000 a dezembro de 2010; (c) seriam analisadas as edições disponibilizadas de forma completa e gratuita no ambiente virtual da internet; (d) seriam descartados os periódicos que apresentassem foco de interesse distante da área de Educação e/ou Educação Matemática.
} 
Com relação às instituições de ensino superior às quais 30 destes autores declararam vínculos em suas obras, destacamos que apenas uma delas está situada fora do Brasil (Universidade do Minho, Portugal), e quanto às brasileiras, 8 localizam-se na região Sudeste, 7 na região Sul, 1 na região Centro-Oeste e 1 na região Nordeste.

Nesse tema (assim como nos demais) verificamos que a grande maioria dos autores/pesquisadores é composta por mulheres (28), o que nos serve como indicação da feminização de pesquisas relacionadas à educação e também como possível explicação da recorrência de olhares sobre a questão gênero se apresentar em meio às análises dessas produções, mesmo quando esse não era o foco do estudo.

De uma forma geral, as produções foram originadas tendo por base pesquisas do tipo qualitativas: revisão bibliográfica, reflexões sobre questões políticas/históricas, relatos de experiência ou mesmo complementos de artigos anteriores desenvolvidos pelos próprios autores.

Vale destacar que, em 16 das 19 produções analisadas nesse tema, houve a apresentação, mesmo que simplificada, de partes da história da EJA como introdução aos temas estudados, com o intuito, muitas vezes declarado, de situar melhor o leitor sobre os debates que seriam feitos em seguida e, ainda, como forma de reiterar o polêmico e muitas vezes controverso desenrolar dos fatos que envolvem essa modalidade de ensino. A utilização nos artigos desse fio condutor histórico apareceu por diversas vezes também, como forma de apresentar e justificar os paradigmas relacionados às formas alternativas de organização curricular que permearam e moldaram a EJA, com grande destaque para as ideias de educação libertadora, de Paulo Freire, e do Programa Etnomatemática, de Ubiratan D'Ambrosio.

Sob um olhar geral das produções, destacamos reiteradas defesas de que a prescrição prévia de um currículo para EJA acabaria por desconsiderar as singularidades, as experiências de vida de seus aprendentes, seus saberes anteriores e as conexões que cada um estabelece entre os conhecimentos. Sob a perspectiva das especificidades da EJA não faria sentido pressupor um trajeto obrigatório, homogeneizante e único para todos em seus diferentes processos e progressos de aprendizagem.

Oliveira (2007) ressalta o fato de que essas especificidades são muitas vezes ignoradas nos currículos escolares por apresentarem o conhecimento fragmentado, organizado numa perspectiva cientificista, excessivamente tecnicista e disciplinarista, o que dificulta o estabelecimento de diálogos entre as experiências, os saberes anteriormente tecidos pelos educandos e os próprios conteúdos escolares. No intuito de superar tais problemas, indica a 
opção pelo currículo em um desenho denominado de "tecitura do conhecimento em rede" (OLIVEIRA, 2007, p. 87), que pressupõe que as informações às quais são submetidos os estudantes só irão constituir conhecimento quando se juntarem a outros "fios” já presentes nas redes de saberes de cada um desses estudantes (seus interesses, suas crenças, valores etc.). Quando isso ocorre, esse conhecimento reveste-se de um sentido próprio, que não será necessariamente aquele que o transmissor da informação pressupõe.

No caso específico da Matemática, por exemplo, para que o ensino da aritmética na EJA se desenvolva nessa perspectiva, seria importante que o docente tenha em mente que seus alunos a utilizam em seu cotidiano e o seu conhecimento está diretamente vinculado à possibilidade de evitar constrangimentos (nas situações de comprar, conferir trocos, por exemplo). Esse reconhecimento e sua utilização em situações concretas poderia ser um grande facilitador da aprendizagem e interesse em ampliar os conhecimentos. Entretanto, é importante frisar que tal forma de trabalho não deve significar a infantilização das atividades pedagógicas e nem mesmo uma minimização para a facilitação inconsistente, visando apenas rasos patamares de conhecimento.

Além da aritmética, podemos citar também a área da geometria, em que Duarte (2004) presenciou no desenvolvimento de seu estudo uma grande inventividade dos estudantes/trabalhadores da construção civil, seja na improvisação de soluções, seja na prática de diversos cálculos relacionados ao trabalho desenvolvido nas obras em que trabalhavam. Entretanto, diversos desses estudantes relatavam suas grandes dificuldades em utilizar os algoritmos para efetuar os mesmos cálculos. Tais problemas nos servem de indicação do distanciamento e certo artificialismo dos cursos de EJA com a vida recheada de Matemática fora da escola. Para tentar diminuir tais problemas, este e outros estudos ressaltaram os possíveis benefícios que poderíamos colher ao utilizar as contribuições da Etnomatemática para desenvolver o currículo que será empregado nos cursos direcionados para esses aprendentes, abrindo espaços para a discussão sobre os "mecanismos que estão ativamente envolvidos na legitimação do que conta como próprio/impróprio, válido/não válido" (DUARTE, 2004, p. 211) na composição do currículo na área de Matemática.

A proposta básica do currículo na área de Matemática para a EJA deveria ter como componentes organizadores seis atividades universais: contar, medir, localizar, desenhar, jogar e explicar, e deve ser estruturado de forma a garantir ampla cobertura dessas ideias desenvolvidas por meio de eixos organizadores dos currículos, relacionados com a cultura extraescolar e com o cotidiano do estudante/trabalhador. 
Estudos ressaltaram que um dos grandes desafios pedagógicos que envolvem a elaboração de currículos para a EJA consistiria no fato de reconhecer o trabalho como princípio educativo. Entretanto, não se pode admitir que a educação seja planejada e desenvolvida para atender apenas às necessidades identificadas no mercado de trabalho, tendo em vista, antes de tudo, os interesses da produção, pois essa prática colocaria esses alunos trabalhadores apenas como objetos da produção e do mercado de trabalho, o que se configuraria como uma opção contrária ao compromisso ético-político de se resgatar a centralidade dos sujeitos no processo educativo.

Com base nessas análises, diversos pesquisadores fizeram a indicação da opção por um "currículo integrado" à formação humana frente às diferentes dimensões da vida do estudante/trabalhador, incluindo o trabalho e a cultura, estando esse projeto educacional comprometido efetivamente com a superação das desigualdades e injustiças sociais.

Denominando de projeto burguês de progresso, Zanardi (2009) destaca que a função reprodutivista da educação escolarizada centrou-se na transmissão de conteúdos que valorizam as competências e criam um único modelo de sociedade em que é natural conviver com as desigualdades. Nesse modelo, o caráter político da educação deveria permanecer ocultado a todo custo e o currículo seria apresentado como um conjunto de conteúdos e técnicas desinteressadas e neutras que poderiam proporcionar ao estudante a aquisição do conhecimento e a melhoria das condições de sua vida.

Porém, é impossível que o currículo escolar se apresente neutro (DI PIERRO, JOIA, RIBEIRO, 2001), como se fosse possível também à escola apresentar-se sempre como um local de plena harmonia, inabalável e distante dos problemas do dia a dia. Tais concepções errôneas geram grandes descompassos entre desejar uma educação de EJA realizada sob um projeto educacional próprio da comunidade escolar na qual a escola esteja inserida e a pretensão de se estabelecer um currículo único e não flexível.

Diversos estudos indicaram ser importante nos questionarmos a respeito das intervenções formativas para EJA pautadas por uma racionalidade meramente cognitiva, instrumental e condicionante. A formação desejada seria aquela que possibilite o desenvolvimento de capacidades que potencializem a descoberta de soluções próprias por parte dos aprendentes, face às situações imprevistas. É o incentivo à iniciativa e à autonomia, numa lógica construtivista de valorização da participação, interação e reflexão, considerando no adulto as suas experiências e saberes como importantes suportes no processo de formação. São esses os desafios contemporâneos que se apresentam para a formação de jovens e adultos 
- buscar as respostas mais adequadas para importantes perguntas: O que se deve ensinar? $\mathrm{O}$ que se deve aprender? Que tipo de pessoas queremos formar e desenvolver? Que tipo de sociedade queremos construir?

Como exemplo de bons resultados de projetos voltados para a EJA e que geraram algumas respostas para tais questões, podemos destacar o apresentado pelos pesquisadores Franzoi et al. (2010), envolvendo uma comunidade pesqueira na região sul do Brasil, em uma escola organizada pela pedagogia da alternância, na qual os alunos intercalam parte do tempo de aprendizagem no ambiente escolar e outra parte em suas comunidades. Projeto considerado como uma experiência que permite uma boa articulação entre ensino-pesquisa-extensão, ao mesmo tempo em que proporciona um desenvolvimento local.

\section{Prescrições curriculares em Educação Matemática para a EJA}

No interior do subgrupo de pesquisa temos identificado que diferentes estudos sobre a Educação de Jovens e Adultos (EJA) têm focado em aspectos sociais e culturais, possivelmente pela concepção de que por atuarem no mercado de trabalho e terem acumulado experiências das relações em sociedade, os alunos dessa modalidade de ensino levam para a sala de aula os conhecimentos produzidos em seus mundo-vida.

Nessa perspectiva, o processo educativo deve conceber a Matemática enquanto um fenômeno social e cultural, produzida no interior dos grupos e nas relações de convivência e sobrevivência entre eles, sendo que a Educação Matemática tem papel fundamental nesse contexto (BISHOP, 1988, 1999; D’AMBROSIO, 2005).

Com relação ao fenômeno cultural, encontramos no educador Alan Bishop suas considerações quanto à Matemática na perspectiva cultural, a qual pode ser concebida a partir de três níveis de cultura: técnico, formal e informal. A cultura técnica da Matemática inclui o conjunto de símbolos e de argumentos que os matemáticos utilizam em suas investigações. Em consequência desse nível, tem-se a cultura formal da Matemática, relacionada aos conceitos matemáticos. Já a cultura informal está relacionada aos conhecimentos ad hoc, portanto, saberes matemáticos particulares de um indivíduo ou grupo. Para Bishop (1988, 1999), o desenvolvimento matemático é resultado de desenvolvimentos produzidos no interior de uma cultura, e no contato e no conflito entre elas, determinados pelos processos de aculturação e enculturação.

Concebemos o termo enculturação "no sentido de um processo dialógico e dinâmico 
em que o contato e o conflito da cultura formal com a cultura informal da Matemática resultam em novos modos de construir os saberes matemáticos" (JANUARIO, 2012, p. 72). Assim, entendemos que o currículo deve possibilitar a enculturação da matemática informal dos alunos da EJA e da matemática formal e que a sala de aula deve se constituir num ambiente enculturador.

Considerar a Matemática como um fenômeno cultural, produto de diferentes modos de saber-fazer contagem, localização, medição, desenhos, jogos e explicação, implica no entendimento que as propostas curriculares para essa área do saber devem promover o processo de enculturação matemática. Com relação às características do currículo que propicie esse processo, Bishop (1999) apresenta cinco princípios do enfoque cultural e três componentes do currículo de enculturação matemática.

O princípio da representatividade está relacionado com a representação da cultura matemática, ou seja, com as ideias simbólicas e teóricas. Já o princípio do formalismo imprime ao currículo enculturador o nível formal da cultura matemática como objetivo, fazendo conexões com o nível informal e introduzindo o aluno no nível técnico. $\mathrm{O}$ princípio da acessibilidade tem como pressuposto que, para ser enculturador, o currículo de Matemática deve ser acessível a todos os alunos e, para isso, nas situações de aprendizagem, a Matemática deve ser tratada de "baixo para cima". O princípio do poder explicativo tem como premissa que o currículo enculturador deve promover a argumentação dos alunos frente às ideias matemáticas. A concepção ampla e elementar é uma extensão do princípio do poder explicativo e, nesse princípio, ao invés de ser exigente e limitado, o currículo de enculturação deve ter uma concepção ampla e elementar.

Quanto aos componentes, o simbólico é baseado nos conceitos matemáticos e se organiza em torno das seis atividades e da tecnologia simbólica derivada dessas atividades; o componente social é baseado em projetos e representa a dimensão histórica do desenvolvimento matemático. É a partir desse componente que se desenvolve a consciência crítica do aluno por meio do exercício da reflexão do emprego da Matemática nos diferentes tempos da sociedade: passado, presente e futuro. O componente cultural, que completa o currículo de enculturação, é baseado em investigações e indica para o aluno como e porque se gerou os conceitos matemáticos.

Entendemos que as contribuições de Alan Bishop no que diz respeito à Matemática na perspectiva cultural, implicam que o processo educativo deve identificar nos jovens e adultos suas produções culturais que podem ser úteis para iniciá-los na cultura formal da Matemática, 
enxergando nessas produções importantes elementos do mundo-vida dos educandos, potencialmente significativos, e que devem ser tratados e contemplados pelo currículo de Matemática. Nesse sentido, realizamos um estudo da Proposta Curricular para a EJA, segundo segmento do Ensino Fundamental $-5^{\mathrm{a}}$ a $8^{\mathrm{a}}$ série, objetivando identificar orientações e sugestões para o desenvolvimento curricular enculturador.

A referida Proposta Curricular é constituída de três documentos: Volume 1 Introdução, que tem por finalidade caracterizar o aluno jovem e adulto e apresentar temas de fundamentos comuns às diferentes áreas para a reflexão do currículo, os quais devem ser analisados e discutidos por gestores e professores; Volume 2 - Língua Portuguesa, Língua Estrangeira, História e Geografia; e Volume 3 - Matemática, Ciências Naturais, Arte e Educação Física.

Passaremos a apresentar a análise que realizamos do Volume 3 - Matemática (BRASIL, 2002), na qual tomamos as ideias de Bishop (1999) como referência, elegendo duas categorias de análise e, para cada uma, descritores referentes à sua presença ou à sua ausência na Proposta: (a) princípios do enfoque cultural do currículo de Matemática: representatividade, formalismo, acessibilidade, poder explicativo, concepção ampla e elementar; e (b) componentes do currículo de enculturação: simbólico, social, cultural.

A parte inicial do Volume 3 - Matemática apresenta o texto "Matemática na Educação de Jovens e Adultos", o qual ressalta ser um direito básico e uma necessidade de todo ser humano aprender Matemática. Por meio dessa aprendizagem é possível a participação em sociedade, nas relações de trabalho e de consumo, no exercício crítico e reflexivo da cidadania. Nessa perspectiva, a Proposta Curricular ressalta a importância de jovens e adultos aprenderem Matemática, não de um modo passivo, mas de modo dialogado, problematizado e reflexivo.

A recomendação para que as situações de aprendizagem não se baseiem na memorização de regras ou estratégias caracteriza a presença de princípios do enfoque cultural do currículo de Matemática. Desse modo, identificamos os princípios da representatividade, quando da recomendação de não enfatizar nas atividades apenas a linguagem matemática, caracterizada por um conjunto de saberes prontos e que impossibilita a compreensão da construção das ideias matemáticas; do formalismo, ao sugerir atividades que articulem diferentes saberes - formais e não formais - para construir estratégias, comprová-las, justificá-las e socializá-las; da acessibilidade e do poder explicativo, no sentido de que construir estratégias e partir para a comprovação e a justificativa possibilitam ao aluno fazer 
diferentes relações entre o novo e o vivenciado em seu contexto sociocultural e, desse modo, compreender que a Matemática pode ser problematizada ao invés de se constituir como um conjunto de regras e técnicas simbólicas; e da concepção ampla e elementar, entendendo que, ao problematizarem a Matemática por meio da construção de ideias, da argumentação e da comprovação, as atividades aplicam as ideias matemáticas em diferentes contextos, partindo de situações próximas da realidade do aluno para a construção de ideias mais complexas.

Encontramos também a presença do componente social do currículo de enculturação quando da recomendação de que aprender Matemática é fundamental para que jovens e adultos exerçam a cidadania e que, para isso, tenham autonomia para tomar a Matemática como uma ciência que "auxilia a compreender informações, muitas vezes contraditórias, que incluem dados estatísticos e a tomar decisões diante de questões políticas e sociais que dependem da leitura crítica e da interpretação de índices divulgados pelos meios de comunicação" (BRASIL, 2002, p. 11).

Para isso, as situações de aprendizagem devem ser elaboradas e desenvolvidas para possibilitar que o aluno utilize as ideias matemáticas para problematizar e compreender os fatos sociais acontecidos ou que venham a acontecer em seu mundo-vida ou na sociedade como um todo (presença do componente social).

No tópico "Ensinar e aprender Matemática na EJA" há recomendações para que os processos de ensino e de aprendizagem devam levar em conta três atores principais e as relações estabelecidas entres eles: o aluno, o professor e o conhecimento matemático, tendo como referência os conhecimentos prévios de jovens e adultos.

Trabalhar as ideias matemáticas a partir dos conhecimentos advindos das diferentes experiências de vida dos alunos, tomando-os como ponto de partida para iniciá-los na cultura formal da Matemática, por meio de um processo articulador entre as culturas informal e técnica caracteriza a presença do princípio do formalismo do enfoque cultural do currículo, bem como do princípio da acessibilidade.

Apoiados em Bishop (1999), sabemos que formular questionamentos, confrontar possibilidades e propor alternativas no processo de resolução de atividade são algumas das características que possibilitam ao aluno explicar os conceitos matemáticos por meio das relações que fazem com seu mundo-vida; o ato de explicar pressupõe utilizar as ideias matemáticas para argumentar a respeito das descobertas. Com isso, identificamos a presença do princípio do poder explicativo do enfoque cultural do currículo. 


\section{Materiais didáticos em Educação Matemática para a EJA}

Se concebermos a sala de aula como um ambiente que promova a aproximação de saberes matemáticos escolares com não escolares e a concebermos como um ambiente que propicie a enculturação matemática, e se tomamos o currículo apresentado, na forma do livro didático, como um recurso que potencializa o intercâmbio desses saberes, faz-se necessário que esse currículo também promova a enculturação matemática.

Nessa perspectiva, realizamos um estudo de duas coleções de livros didáticos destinados à Educação de Jovens e Adultos, aprovados pelo primeiro Programa Nacional do Livro Didático para essa modalidade de ensino (PNLD-EJA): a coleção Viver, Aprender, da editora Global em parceria com a Ação Educativa, editada em 2009; e a coleção Tempo de Aprender, da editora IBEP, tendo sua segunda publicação em 2009. Ambas as coleções são obras coletivas, destinadas ao segundo segmento do Ensino Fundamental.

Elegemos duas categorias de análise, uma fundamentada em Bishop (1999), referente aos componentes do currículo de enculturação (simbólico, social e cultural), e a outra fundamentada em Skovsmose (2008) quanto à escolha de contexto das atividades propostas pelos livros: matemática pura, realidade e semirrealidade, nos dois cenários: paradigma do exercício e investigação.

Esses dois cenários juntamente com os três contextos formam seis ambientes de aprendizagem, conforme ilustramos no quadro 1. Para o autor, a expectativa em relação ao ensino de Matemática "é de que a busca de um caminho entre os diferentes ambiente de aprendizagem possa proporcionar novos recursos para levar os alunos a agir e a refletir, oferecendo, dessa maneira, uma educação matemática de dimensão crítica" (SKOVSMOSE, 2008, p. 39).

\begin{tabular}{|c|c|c|}
\cline { 2 - 3 } \multicolumn{1}{c|}{} & Paradigma do Exercício & $\begin{array}{c}\text { Paradigma da } \\
\text { Investigação }\end{array}$ \\
\hline $\begin{array}{c}\text { Referências à } \\
\text { matemática pura }\end{array}$ & ambiente I & ambiente II \\
\hline $\begin{array}{c}\text { Referências à } \\
\text { semirrealidade }\end{array}$ & ambiente III & ambiente IV \\
\hline
\end{tabular}




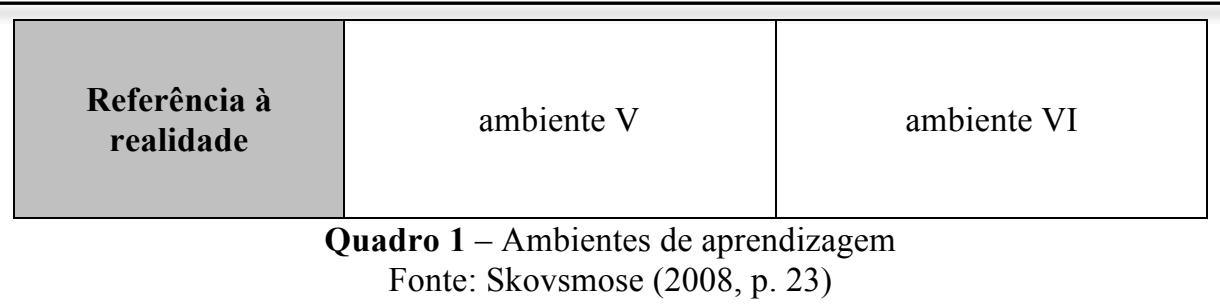

Com relação à primeira categoria, nosso objetivo foi de identificar as ideias subjacentes na abordagem dos conteúdos e nas atividades apresentadas pelo livro didático, quanto à enculturação. É, antes, uma tentativa de explicitar essas ideias subjacentes que, de alguma forma, se fazem presentes nesses materiais, e não um juízo de valor por contemplar ou não esses componentes.

Quanto à análise das duas coleções de livros, entendemos que apresentar conceitos matemáticos por meio das seis atividades elencadas por Bishop (1999) - contar, medir, localizar, desenhar, jogar e explicar - são características da presença do componente simbólico no currículo enculturador. Identificamos em ambas as coleções, situações-que fazem uso dessas atividades em diferentes momentos em suas abordagens.

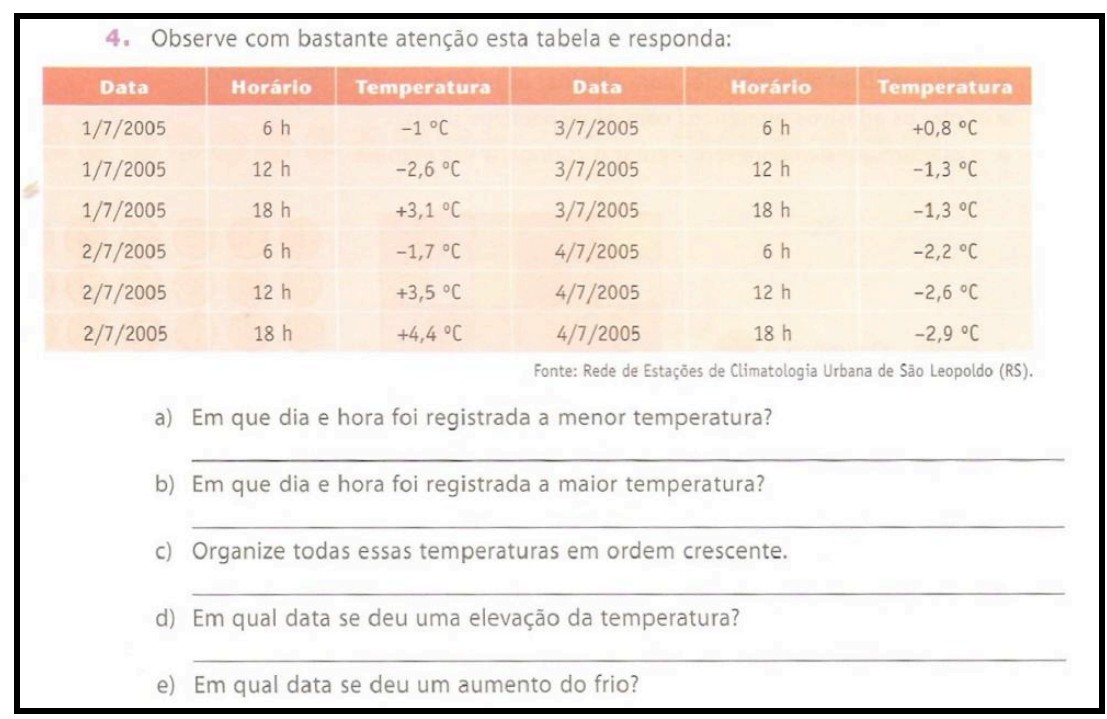

Figura 1 - Números negativos e positivos

Fonte: Tempo de Aprender - $7^{\circ}$ ano (PACHI; VALENTINI, 2009, p. 167)

As abordagens presentes na figura 1 apresentam operações com números inteiros, ideias relacionadas aos números positivos e negativos, correspondência, unidades de medida, localização na reta e sentido positivo ou negativo. Esses conceitos estão atrelados às atividades de contar, localizar e medir.

Atividades envolvendo sequências numéricas, padrões e regularidades, aparecem em diferentes momentos nos livros didáticos, principalmente na coleção "Viver, Aprender". Identificamos esse tipo de abordagem em algumas situações, como, por exemplo: 


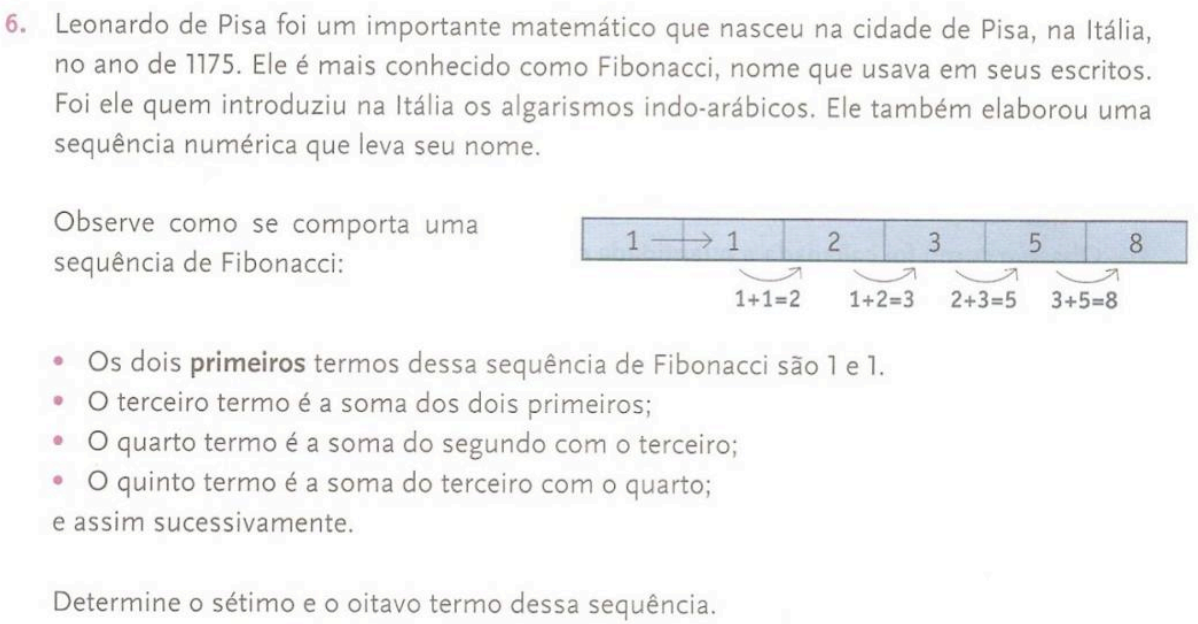

Situações como essas permitem aos alunos a exploração e a investigação, propiciando os atos de conjecturar, generalizar e outros afins. Bishop (1999) propõe algumas ideias para investigações da cultura matemática, dentre as quais podemos destacar: Números figurados (triangular, quadrados), Sequência de Fibonacci e Probabilidades experimentais. Essas ideias foram contempladas nas abordagens e atividades propostas pelos livros analisados, o que caracteriza a presença do componente simbólico e cultural.

Algumas atividades apresentadas nessas coleções partem de situações do entorno do aluno, fator favorável à acessibilidade dele ao saber matemático. Observamos um exemplo dessa situação numa atividade intitulada "Utilizando um guia de ruas" (Onaga e Meireles, 2009, p. 150). Identificamos, nessas situações, a atividade de localizar. Vale salientar que os autores utilizam essa situação também para empregar conceitos matemáticos tais como: circunferência, retas, segmentos de retas, retas paralelas, concorrentes e perpendiculares, entre outros. Essa é uma atividade de exploração, o aluno estuda o mapa, faz traçados, expressa a ideia de coordenadas, direção (horizontal, vertical), sentido (norte, sul, leste, oeste). O aluno, portanto, partindo de uma situação que é do seu cotidiano, explora conceitos matemáticos e desenvolve a atividade de medir.

Essa abordagem, além de incluir as atividades sociais, que para nós caracteriza a presença do componente simbólico, pode, também, propiciar ao aluno a percepção do uso que a sociedade faz do conhecimento matemático, o que para nós implica o componente social.

Podemos identificar, a partir dessas reflexões que, de uma maneira geral, os livros analisados apresentam os componentes simbólico, cultural e social essenciais para um currículo enculturador. Como pudemos observar nas diferentes abordagens e atividades 
contidas no material, esses componentes aparecem com mais ênfase em algumas atividades do que em outras, ou ainda, em alguns momentos existe a presença de um componente, em outros há uma interação entre alguns dos componentes. Existem ainda aqueles momentos nos quais não conseguimos identificar esses componentes em questão.

Quanto à categoria relacionada à escolha de contextos, apresentaremos alguns exemplos, para os ambientes de aprendizagem, que apareciam com maior frequência nas duas coleções. Ressaltamos, porém, que tratam de atividades presentes nos livros didáticos, e não da prática efetiva do professor em sala de aula. Por isso, algumas questões que consideramos propícias a uma investigação podem não acontecer efetivamente em sala de aula, pois isso dependerá da postura do professor frente às situações de aprendizagem.

Identificamos, nas duas coleções, atividades que caracterizam o paradigma do exercício, num contexto que se refere à matemática pura. Nesse ambiente (I), dominam atividades em que predominam o uso de procedimentos, algoritmos, regras, fórmulas, e outros. As atividades são aplicáveis no próprio contexto matemático.

O ambiente (II) de aprendizagem voltado para investigação, cujas referências estão na matemática pura, são aqueles em que predominam questões abertas, cuja solução depende da criação de estratégias de resolução pelos alunos e atividades que envolvem principalmente números e figuras geométricas. Essa característica foi identificada em atividades, como à apresentada anteriormente na Figura 2. Quanto ao ambiente do tipo III, apresentamos o seguinte exemplo:

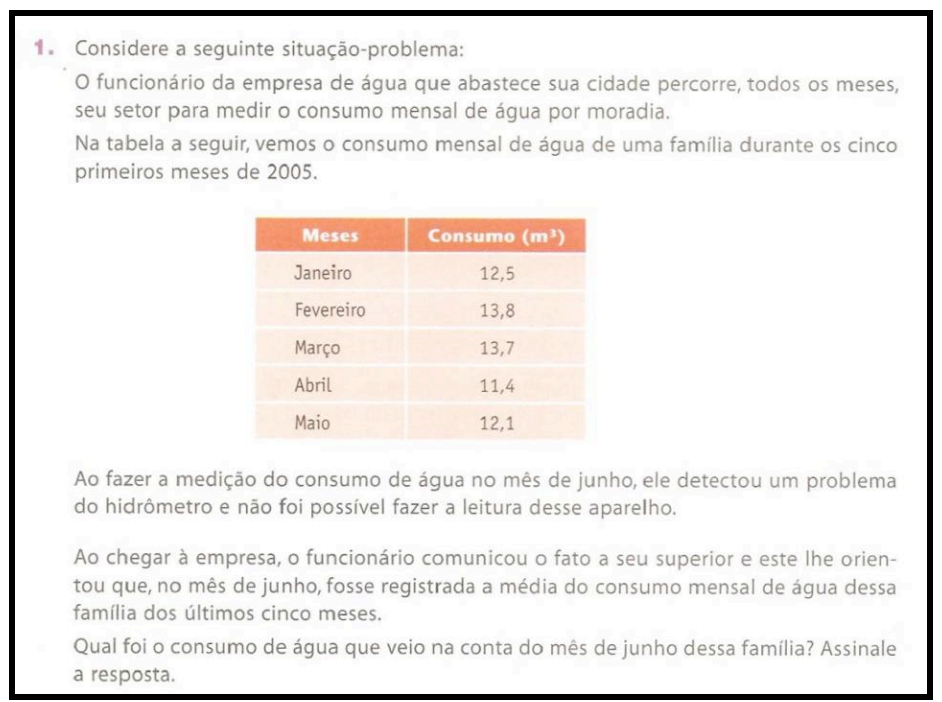

Figura 3 - Atividade com característica do ambiente III Fonte: Tempo de Aprender - $9^{\circ}$ ano (PACHI; VALENTINI, 2009, p. 93)

Esse ambiente representa o paradigma do exercício com referências à semirrealidade, no qual dominam atividades como, por exemplo, compras, vendas, cálculo de áreas a serem 
pintadas, mas são situações artificiais e, sendo assim, os exercícios estão localizados numa semirrealidade. Os dados contidos nos exercícios são artificiais. No entanto, mesmo contendo situações hipotéticas, esse contexto da semirrealidade, pode propiciar ao aluno um melhor desempenho nas atividades e ajudá-los na resolução de problemas.

Apesar de algumas atividades se caracterizarem pelo paradigma do exercício, algumas delas "podem provocar atividades de resolução de problemas, as quais poderiam transformarse em genuínas investigações matemáticas" (SKOVSMOSE, 2008, p. 31). Como nossa análise se refere aos livros didáticos, não conseguimos chegar a essas conclusões, uma vez que podem acontecer também situações contrárias. Assim, as atividades que porventura identificamos como propícias à investigação, na sala de aula podem tornar-se características do paradigma do exercício, pois o responsável pela mediação é o professor.

Não foram encontradas situações que caracterizam o ambiente do tipo (VI) em nenhuma das coleções. Caracterizado pela investigação com referências à realidade, esse ambiente apresenta situações de aprendizagem que enfatizam experiências vivenciadas pelos alunos, objetivando a investigação na perspectiva de projetos. As situações nesse ambiente são reais, "tornando possível aos alunos produzir diferentes significados para as atividades (e não somente aos conceitos)" (SKOVSMOSE, 2008, p. 30). Nesse ambiente, o papel do professor é orientar e instigar os alunos a novas discussões baseadas na investigação.

\section{Considerações finais}

Nossos estudos no interior do subgrupo de pesquisa indicam cada vez mais frequente o debate sobre a Educação de Jovens e Adultos (EJA), principalmente ao que se refere a ações de erradicação do analfabetismo, metodologia e tratamento adequado dos conteúdos, para que se atendam as necessidades de aprendizagem desses alunos. Porém, ainda consideramos pequeno o número de pesquisas no âmbito da organização e desenvolvimento curricular de Matemática para essa modalidade.

Com relação ao currículo de Matemática para a EJA, entendemos que estudos de pesquisas e de documentos curriculares sobre/para essa modalidade de ensino contribuem para identificarmos o que tem sido produzido acerca da Educação Matemática de pessoas jovens e adultas, e que aspectos sociais e culturais são considerados para elaborar e desenvolver situações de aprendizagem que promovam a produção de conhecimentos a partir 
da legitimação dos saberes que esses alunos constroem ao longo de sua experiência com e no mundo.

Como resultados dos três estudos aqui apresentados, destacamos que, de uma forma geral, as ideias que permearam as produções analisadas referentes ao currículo de Matemática para a EJA, independente do foco de análise adotado ou dos referencias teóricos utilizados, ressaltam a crença e a esperança de ser possível termos uma escola que se preocupe em desenvolver e implementar um currículo que leve o aluno a entender a importância de se ampliar sua gama de conhecimentos, porque perceberão que eles estão de fato relacionados de alguma forma a sua realidade, nas diferentes dimensões (social, política, cultural). Alguns autores chegaram a apresentar seus votos de que essa esperança cresça na mesma proporção das discussões sobre a EJA e que resultem em um processo democrático de acesso ao conhecimento e às oportunidades de melhoria de vida de seus alunos. Entretanto, as propostas apresentadas nos estudos ainda se apresentam bastante vagas como, por exemplo, a de que alguns conteúdos formais clássicos devem ser substituídos por outros que possam melhor contribuir para estes objetivos, e que o distanciamento do "saber enciclopédico" não deve significar uma minimização ou facilitação de conteúdos, mas sim uma adequação consistente de conteúdos vinculados ao "mundo da vida".

Com relação às prescrições curriculares, a Proposta Curricular para a EJA apresenta recomendações que, para uma formação emancipadora, precisariam de situações de aprendizagem elaboradas considerando o enfoque cultural da Matemática por meio de atividades que enfatizem diversas explicações, teorizações, ideias intuitivas e seguridade para explicar fenômenos e os porquês matemáticos; que trabalhem os conceitos de modo articulados com os diferentes saberes (informais, formais e técnicos); que partam do contexto do aluno para o contexto matemático; que apresentem explicações dos conceitos e ideias matemáticas promovendo a habilidade para, ao fazer relações, explicar situações vivenciadas em seu meio social e, desse modo, que sejam estabelecidas conexões entre diferentes contextos. Também identificamos, nas diversas recomendações, a presença de componentes enculturadores, como nas orientações para que as situações de aprendizagem apresentem os conceitos e as ideias matemáticas de modo inter-relacionados entre si por meio das diferentes atividades de saber-fazer matemática; para que proponha atividades articuladas dos fatos sociais, problematizando-os, tomando-os como exemplos para explicar alguns conceitos; e para que solicitem o desvendar das ideias matemáticas por meio de problemas investigativos.

Identificamos, também, nos livros didáticos analisados, abordagens que contemplam 
componentes do currículo que favorecem à enculturação matemática, porém o enfoque não foi dado durante toda abordagem dos conteúdos ou de atividades e situações de aprendizagens propostas.

Quanto aos cenários e contextos, que se fizeram presentes nas duas coleções didáticas, apesar de o ambiente do tipo III ser o mais evidenciado nas duas coleções, percebemos, também, em muitos momentos, abordagens e atividades propensas aos ambientes II e IV. Percebemos uma tendência, mesmo que genuína, no cenário da investigação no contexto da matemática pura e da semirrealidade.

É importante que os currículos de Matemática para a Educação de Jovens e Adultos sejam construídos de modo a respeitar o lugar social e cultural desse educando; que representem a cultura matemática; que sejam acessíveis ao aluno; que formalizem os conceitos de forma apropriada à construção do conhecimento; que os conceitos sejam construídos a partir de atividades ricas e significativas.

Outro ponto que merece estudo e debate é a relação que os professores de Matemática estabelecem com os documentos curriculares para a EJA. A nosso ver, as prescrições curriculares têm como finalidade orientar - por meio de sugestões didáticas, metodológicas e conceituais - os diferentes atores do processo educacional (gestores, coordenadores pedagógicos, autores de materiais, professores, comunidade acadêmica) a organizar e desenvolver currículos que atendam as reais necessidades de aprendizagem de jovens, adultos e idosos. Os livros didáticos, como currículo, têm papel fundamental para a prática do professor ao elaborar e desenvolver situações de aprendizagem, pois são esses materiais que traduzem, como atividades, as prescrições curriculares.

Nesse sentido, a relação estabelecida entre professores e materiais curriculares precisa ser tomada como problema de pesquisa, cujo objetivo seja o de identificar como esses profissionais se apropriam das orientações desses materiais; que uso fazem deles e porque o fazem; e o que eles consideram como relevante ao selecionar determinado material para apoiar o desenvolvimento de suas aulas de Matemática.

\section{Referências}

BISHOP, A. J. Aspectos sociales e culturales de la Educación Matemática. Enseñanza de las Ciencias, Barcelona, v. 6, n. 2, p. 121-125, 1988.

BISHOP, A. J. Enculturación matemática: la educación matemática desde una perspectiva cultural. Traducción de Genis Sánchez Barberán. Barcelona: Paidós, 1999. 
BRASIL. Lei $\mathbf{n}^{\mathbf{0}} \mathbf{. 9 . 3 9 4}$, de 20 de dezembro de 1996. Estabelece as diretrizes e bases da educação nacional. Diário Oficial da União, Brasília, 23 dez. 1996.

BRASIL. Resolução CNE/CEB no ${ }^{0}$ 1, de 5 de julho de 2000. Estabelece as Diretrizes Curriculares Nacionais para a Educação e Jovens e Adultos. Diário Oficial da União, Brasília, 19 jul. 2000.

BRASIL. Secretaria de Educação Fundamental. Proposta Curricular para a educação de jovens e adultos: segundo segmento do ensino fundamental: $5^{\mathrm{a}}$ a $8^{\mathrm{a}}$ série: Matemática, Ciências, Arte e Educação Física. v. 3. Brasília: MEC, 2002.

CHARTIER, R. Práticas da Leitura. São Paulo: Estação Liberdade, 2009.

D’AMBRÓSIO, U. Sociedade, cultura, matemática e seu ensino. Educação e Pesquisa, São Paulo, v. 31, n. 1, p. 99-120, jan./abr. 2005.

DI PIERRO, M. C.; JOIA, O.; RIBEIRO, V. M. Visões da Educação de Jovens e Adultos no Brasil. Cadernos CEDES, Campinas, v. 21, n. 55, p. 58-77, nov. 2001.

DUARTE, C. G. Etnomatemática, currículo e práticas sociais do mundo da construção civil. Educação UNISINOS, São Leopoldo, v. 5, n. 9, p. 195-215, jul./dez. 2004.

FRANZOI, N. L.; HYPOLITO, A. M.; FISCHER, M. C.; PINO, M. D.; SANTOS, S. V. Escola, Saberes e Trabalho: a pesquisa do PROEJA no Rio Grande do Sul. Educação e Realidade, Porto Alegre, v. 35, n. 1, p. 167-186, jan./abr. 2010.

FREITAS, A. V. Educação Matemática e Educação de Jovens e Adultos: estado da arte de publicações em periódicos (2000 a 2010). 2013. 360 f. Tese (Doutorado em Educação Matemática) Programa de Estudos Pós-Graduados em Educação Matemática. Pontifícia Universidade Católica de São Paulo, São Paulo, 2013.

GIL, A. C. Métodos e técnicas de pesquisa social. 6. ed. São Paulo: Atlas, 2008.

HADDAD, S. O estado da arte das pesquisas em Educação de Jovens e Adultos no Brasil: a produção discente da pós-graduação em educação no período 1986 - 1998. São Paulo: Ação Educativa, 2000.

JANUARIO, G. Currículo de Matemática da Educação de Jovens e Adultos: análise de prescrições na perspectiva cultural da Matemática. 2012. 156 f. Dissertação (Mestrado em Educação Matemática) - Programa de Estudos Pós-Graduados em Educação Matemática. Pontifícia Universidade Católica de São Paulo, São Paulo, 2012.

MORAES, R.; GALIAZZI, M. C. Análise textual discursiva. 2. ed. Rio Grande do Sul: Unijuí, 2011.

OLIVEIRA, I. B. Reflexões acerca da organização curricular e das práticas pedagógicas na EJA. Educar em Revista, Curitiba, n. 29, p. 83-100, maio 2007.

ONAGA, D. S.; MEIRELES, H. H. Educação de Jovens e Adultos: segundo segmento do ensino fundamental. São Paulo: Global/Ação Educativa, 2009. (Coleção Viver, Aprender).

PACHI, C. G. F.; VALENTINI, S. M. F. Educação de Jovens e Adultos: $6^{\circ}$ ao $9^{\circ}$ ano do ensino fundamental. 2. ed. São Paulo: IBEP, 2009. (Coleção Tempo de Aprender). 
ROCHA, M. A.; SALVI, R. F. Panorama atual sobre os trabalhos de campo em periódicos da área de ensino de ciências (2005 - 2009). In: ENCONTRO NACIONAL DOS GEÓGRAFOS, 16., 2010, Porto Alegre. Anais do XVI AGB, São Paulo, 2010, p. 1-10. Disponível em $<$ http://www.agb.org.br/xvieng/anais>. Acesso em: 22 jul. 2011.

SANTANA, K. C. L. Currículo de Matemática da Educação de Jovens e Adultos: uma análise baseada em livros didáticos. 2012. 137 f. Dissertação (Mestrado em Educação Matemática) Programa de Estudos Pós-Graduados em Educação Matemática. Pontifícia Universidade Católica de São Paulo, São Paulo. 2012.

SKOVSMOSE, O. Desafios da Reflexão em Educação Matemática Crítica. Tradução: Orlando de Andrade Figueiredo e Jonei Cerqueira Barbosa. Campinas: Papirus, 2008.

ZANARDI, T. A. C. Currículo e inclusão. Trabalho \& Educação, Belo Horizonte, v. 18, n. 2, p. 121132, maio/ago. 2009.

Submetido em Agosto de 2013. Aprovado em Janeiro de 2014. 